\title{
Instrumental methods in the diagnostics of special vehicle drive
}

\author{
Jiri Stodola ${ }^{1, *}$ and Zdenek Krobot ${ }^{2}$ \\ ${ }^{1}$ University of Defence Brno, Department of Combat and Special Vehicles, Kounicova Str. 65, 66210 Brno, Czech Republic \\ ${ }^{2}$ University of Defence Brno, Department of Combat and Special Vehicles, Kounicova Str. 65, 66210 Brno, Czech Republic
}

\begin{abstract}
The article deals with selected possibilities of diagnostics of the integrated power pack of special vehicles using advanced instrumental tribotechnical diagnostic methods. Fourier Transformation Infrared Spectrometry (FTIR), Ferrography, Atomic Emission Spectrometry (AES) and Laser Counter and Laser-Net Fines were used to analyse used oil samples. The analyses were focused on objective evaluation of the technical state of the monitored systems as well as the degree of degradation of the oils used in these systems.
\end{abstract}

\section{Introduction}

The increasing complexity of machinery and the cost of maintenance and repair motivate the users to know the technical state of the device in real time. It is desirable to diagnose the equipment with minimal constraints on its operation and in a short period of time, especially for special technology applications. The development of electronics, information technology and telematics has enabled the rapid development of non-destructive, nondisassembly methods of technical diagnostics. Tribotechnical diagnostics, which is a widely used and promising method, uses the lubricating medium as a source of multidimensional complex information on the technical condition and wear regime of the system, and about the actual condition of the lubricating medium. From the diagnostic point of view, it is desirable to monitor the size of wear particles in the oil samples and the ratio of contents of large and small particles. The wear particles are divided into fine and coarse materials as shown in Figure 1. General model of the closed lubrication system is shown in Figure 2. For analyzing the size, morphology and shape of the particles analytical ferrography is used, as well as the new LNF-C automatic oil level analyzers, Figure 3 , and its principle in Figure 4. Due to the different mechanisms of component wear, we can find a completely different and typical spectrum of wear particles. Atomic emission (absorption) spectrometers (AES), Figure 5, or polarographs are used to get the information on the content of abrasion metals, contaminants and additives.

Tribotechnical diagnostics includes methods that allow us to judge the wear of the engine, gear, or hydraulic system based on the results of analyzes of regularly extracted oil samples, to assess the technical condition, to predict the occurrence of breakdowns, accidents and the degree of degradation of functional properties of the oil $[1,2,3]$.

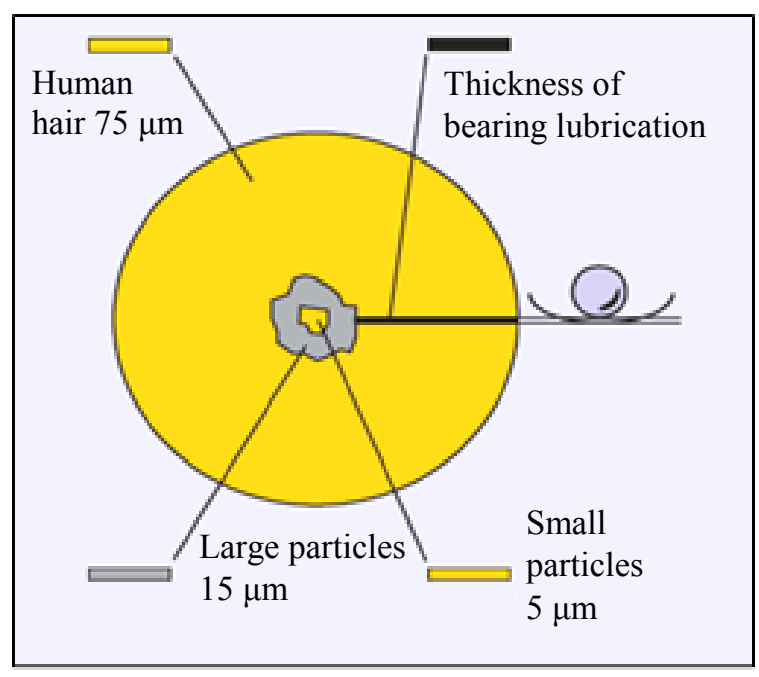

Fig. 1. Wear particles size.

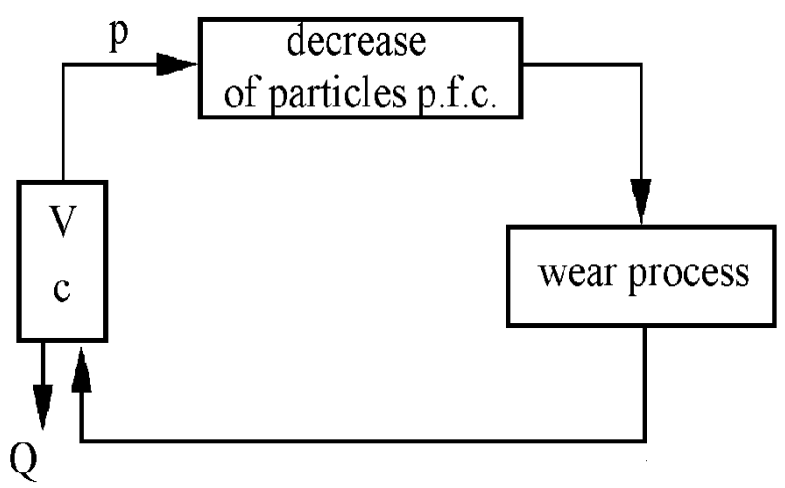

Fig. 2. Model of lubrication system (V - volume of lubrication system, $\mathrm{c}-$ concentration of wear products over time, $\mathrm{f}-$ particle removal coefficient, $\mathrm{p}$ - amount of oil delivered to friction pairs, $\mathrm{Q}-$ oil loss).

\footnotetext{
* Corresponding author: jiri.stodola@,unob.cz
} 


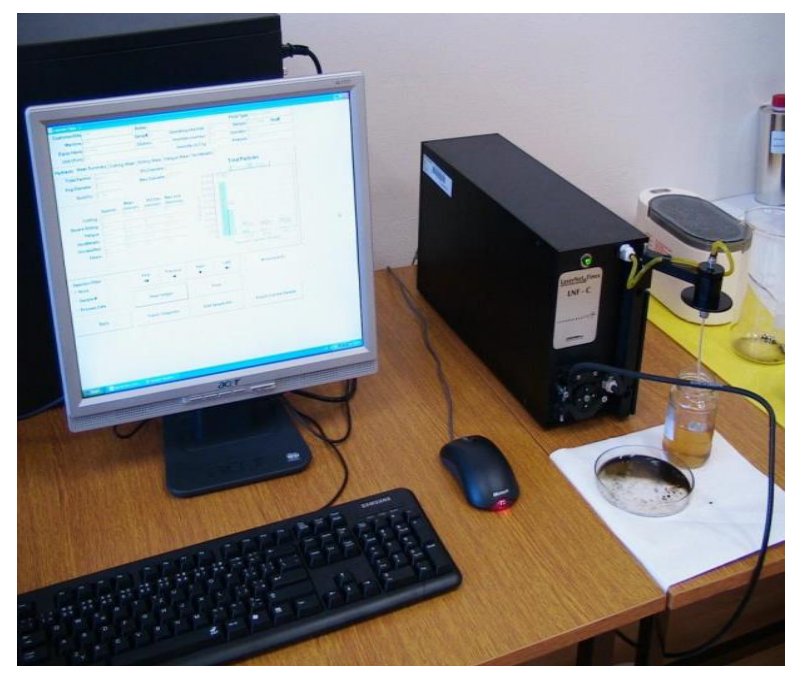

Fig. 3. Laser counter and particle classifier.

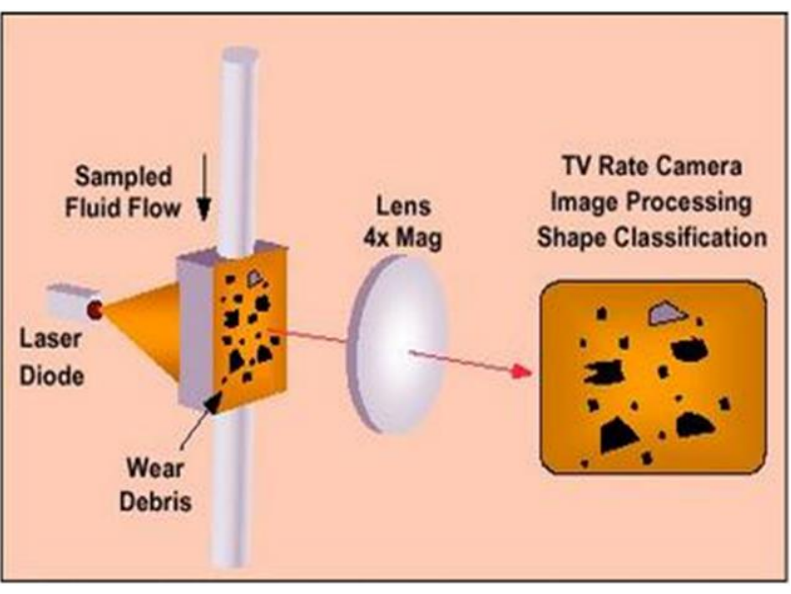

Fig. 4. Principle of laser counter and classifier.

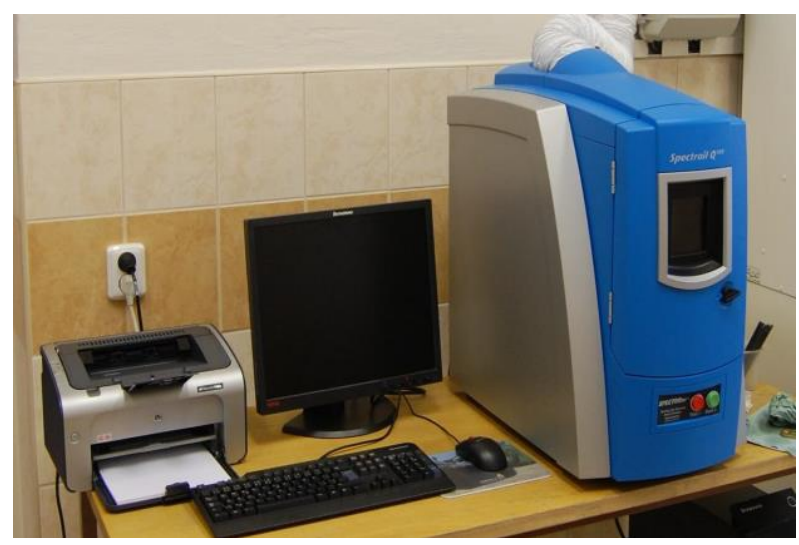

Fig. 5. Atomic emission spectrometer.

The results of oil analyzes serve primarily to accomplish the following tasks [4], [5]:

1. Reduction of maintenance costs. By detecting the malfunction in its early stages, we can save costs:

- by preventing total destruction of the device,
- by limiting secondary damage (a malfunction of one small component can eventually cause extensive damage to the entire device; for example, if a defective crankshaft bearing is detected and the worn crankshaft replaced in time, it saves a large amount of money because it does not destroy the much more expensive crankshaft).

2. Wear monitoring. Determination of the abrasive metal content in the lubricant.

3. Determining the life of the lubricant. Determining the degree of its degradation by operation, mainly by products of thermooxidation processes, external impurities, etc.

4. Determination of optimal time limits for the exchange of lubricants. This aspect is gaining momentum especially in today's increasing oil prices and extensive austerity measures.

5. Increase in security. Serious malfunctions of some device may endanger the life and health of the operators, e.g. aviation engines, compressors, generators, some hydraulic systems, etc.

\section{Tribotechnical diagnostics parameters}

The external and unwanted product of the mechanical system is a very a wide range of wear particles. From a diagnostic point of view, it is important that these particles can provide comprehensive information on the status of individual friction pairs of the device. The methods of tribotechnical diagnostics, applicable for the detection of conditions of a complicated closed mechanical system, e.g. a driving system, can be divided according to Table 1 .

Table 1. Selected method of tribotechnical diagnostics.

\begin{tabular}{|c|c|c|}
\hline Simple methods & $\begin{array}{c}\text { Standardized } \\
\text { methods }\end{array}$ & $\begin{array}{c}\text { Special } \\
\text { methods }\end{array}$ \\
\hline $\begin{array}{c}\text { Contractual } \\
\text { viscosity }\end{array}$ & $\begin{array}{c}\text { Kinematic } \\
\text { viscosity }\end{array}$ & IR spectrometry \\
\hline Total pollution & Flash point & Polarography \\
\hline $\begin{array}{c}\text { Determination of } \\
\text { water }\end{array}$ & Acidity, alkalinity & Ferrography \\
\hline $\begin{array}{c}\text { Contend of } \\
\text { substances } \\
\text { insoluble in hexane }\end{array}$ & $\begin{array}{c}\text { Conradson } \\
\text { carbonization test } \\
\text { CCT }\end{array}$ & $\begin{array}{c}\text { Atomic } \\
\text { absorption of } \\
\text { emission } \\
\text { spectrometry }\end{array}$ \\
\hline $\begin{array}{c}\text { Detergent- } \\
\text { dispersion } \\
\text { properties }\end{array}$ & Water content & $\begin{array}{c}\text { Other methods } \\
\text { (radionuclides } \\
\text { etc.) }\end{array}$ \\
\hline
\end{tabular}

\section{Instrumental methods of diagnostic}

\subsection{FTIR method}

Infrared spectrometry is an analytical technique designed primarily for the identification and structural characterization of organic compounds as well as for the determination of inorganic substances. This technique measures the absorption of infrared radiation of different wavelengths passing through the analyzed sample. The 
principle of the method is the absorption of infrared radiation when passing through the sample. Interaction of infrared radiation with molecules or characteristic groups of molecules causes their excitation to higher vibrational levels [6]. This is due to the absorption of radiation with certain energy values, and the so-called vibration bands are created in the spectrum. The position of these bands indicates what substances are involved. The analytical output of the method is the infrared spectrum, which is a graphical representation of the functional dependence of energy, mostly expressed as percentage of transmittance (T-permeability) or absorbance units $(A=1 / T)$ on the wavelength of the incident radiation. To measure samples that strongly absorb infrared radiation (aqueous solutions, emulsions), the technique of Attenuating Total Reflectance (ATR) is advantageous. The technique is based on the principle of multiple full reflection of the radiation on the phase interface of the measured sample and the measurement crystal from high refractive index material. The crystal is usually in the shape of a trapezoidal prism. The beam of rays is fed into the crystal by a system of mirrors so that the angle of incidence on the phase interface satisfies the condition of total reflection. In the total reflection at the interface of two environments (thicker - crystal and thinner - sample) there is the so called evanescent wave of electromagnetic radiation in the area of absorption. When analyzing engine oil samples, we focus on the so called "fingerprint region". These are absorption bands in the area of $1500-400 \mathrm{~cm}^{-1}$, Figure 6 [7]. This area is characteristic for individual types of oils and their additives. Infrared spectrometry has a wide range of uses, detects changes in oil composition, additive content, contamination by liquids, water concentration, this method can identify thermal degradation of oil, excessive wear and engine load.

Table 2. Values of wavenumbers for selected compounds [8].

\begin{tabular}{|c|c|c|}
\hline Position $\left(\mathrm{cm}^{-1}\right)$ & Compound & Note \\
\hline $3640-3540$ & Water & In ester oils \\
\hline $3600-3400$ & Water & In petroleum oils \\
\hline 3450 & Ester decomposition & \\
\hline 2000 & Soot & \\
\hline $1800-1680$ & Oxidation products & \\
\hline 1748 & Esters & $\begin{array}{l}\text { Synthetic } \\
\text { compounds }\end{array}$ \\
\hline $1650-1600$ & Nitric compounds & \\
\hline $1180-1120$ & Sulphur products & $\begin{array}{c}\text { Sulphur } \\
\text { additives and in } \\
\text { fuel }\end{array}$ \\
\hline 1070,1040 (pair) & Ethylene glycol & Coolant \\
\hline $1025-960$ & Anti-wear additives & (ZDDP) \\
\hline 1000 & $\begin{array}{l}\text { High temperature } \\
\text { oxidants }\end{array}$ & (ZnDDF) \\
\hline $990-960$ & Anti-wear datives & $\begin{array}{c}\text { (TPC- } \\
\text { trikresylfosfat }\end{array}$ \\
\hline $815-805$ & Diesel & \\
\hline $755-748$ & Kerosene & $\begin{array}{c}\text { Lighter } \\
\text { components }\end{array}$ \\
\hline
\end{tabular}

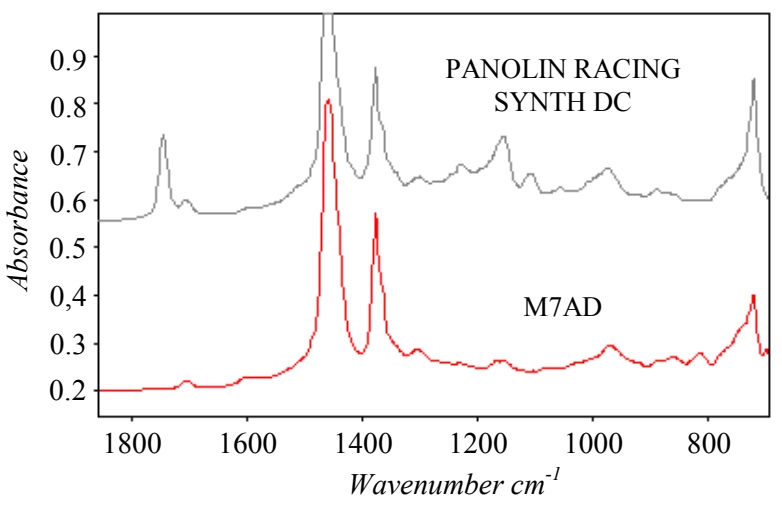

Fig. 6. Example of oil spectrum.

\subsection{Analytical ferrography}

From the diagnostic point of view, the oil should be tested by a suitable method for determining the content, amount, morphology, etc. of particles present in the samples taken. The most preferred method is ferrography, Figure 7. Ferrography uses a highly gradient magnetic field to attract and retain metal wear particles from a sample of fluid (oil) flowing down a specially modified plate tilted at a small angle in the direction of its longer edge. Two methods can be used for particle analysis, either feroscopic or ferodenzimetric method. Example of cutting wear particle is in Figure 8 [9]. The entry area where the oil touches the glass for the first time is approximately $56 \mathrm{~mm}$ from the outlet where it leaves the drain tube. Here the largest magnetic particles are also captured because the magnetic force that attracts them is proportional to their magnitude. Large particles are captured earlier, and when the fluid sample reaches $50 \mathrm{~mm}$, most particles larger than 2-3 $\mu \mathrm{m}$ (in the main dimension) are already captured.

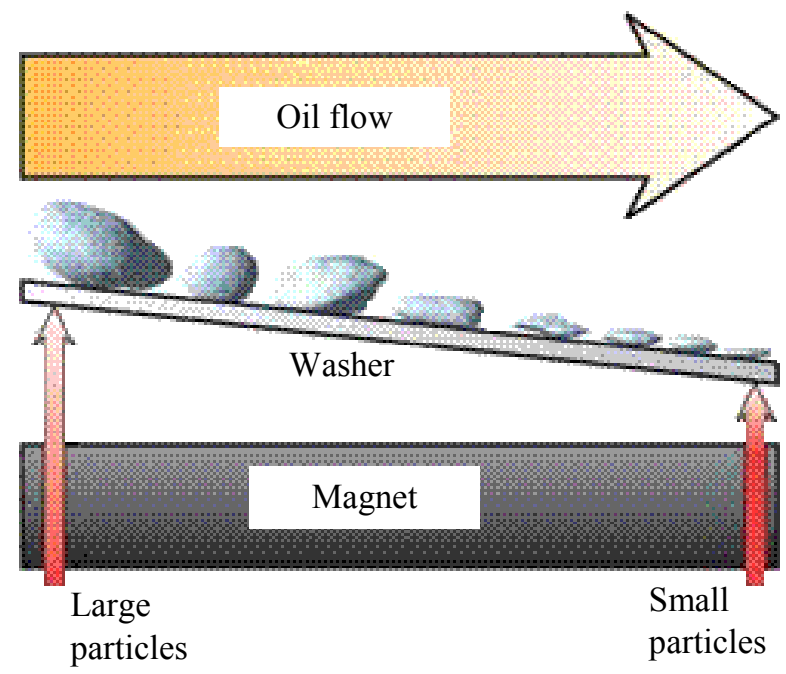

Fig. 7. Principle of ferrography. 


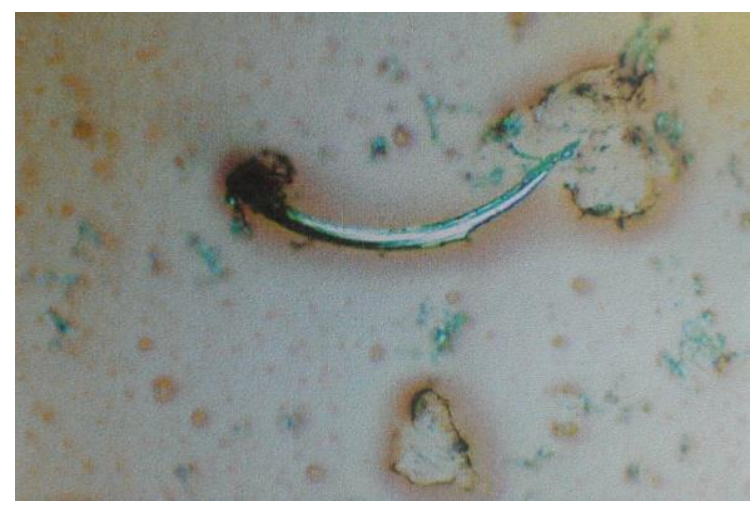

Fig. 8. Example of cutting wear particle.

\section{Selected results}

As an example, a signature method has been selected - it is based on the recognition of objects, events, or processes by using a set of numbers describing the properties of the object. Technical state patterns are given by $n$-dimensional vectors of numerical values of diagnostic quantities recorded in different parts of a diagnosed object at the same time $[9,10]$. In matrix form the technical state pattern is defined by a column vector

$$
x=\left[x_{1}, x_{2}, \ldots, x_{\mathrm{n}}\right]^{\mathrm{T}},
$$

where numbers $x_{1}, x_{2}, \ldots, x_{\mathrm{n}}$ are diagnostic characteristics magnitudes, or calculated characteristics determining vector coordinates in $\mathrm{n}$-dimensional space. Single process recognition classes correspond with single diagnoses of technical states of a diagnosed object [11]. The diagnoses set $D$

$$
D=\left\{D_{1}, D_{2}, \ldots D_{\mathrm{R}}\right\}
$$

is explicitly classified as belonging to a diagnoses indicators set $D$. Then the decision rule $D_{\mathrm{i}}=\mathrm{s}(\mathrm{x})$ matches each specific signature vector with a corresponding diagnose - state indicator. The diagnose indicator is transformed into a corresponding diagnose technical state code.

Table 3. Input data of soot particles.

\begin{tabular}{|c|c|c|c|}
\hline Sample & Soot (\%) & Sample & Soot (\%) \\
\hline 1 & 0.031771816 & 11 & 0.240091324 \\
\hline 2 & 0.103316583 & 12 & 0.234781966 \\
\hline 3 & 0.125431612 & 13 & 0.256827921 \\
\hline 4 & 0.1473445 & 14 & 0.107033946 \\
\hline 5 & 0.168435231 & 15 & 0.166212305 \\
\hline 6 & 0.13423948 & 16 & 0.193901226 \\
\hline 7 & 0.137344524 & 17 & 0.235333502 \\
\hline 8 & 0.138561517 & 18 & 0.250645906 \\
\hline 9 & 0.182563171 & 19 & 0.263931781 \\
\hline 10 & 0.240091324 & 20 & 0.282059491 \\
\hline
\end{tabular}

For the practical application of the method, it is necessary to choose the optimal number of diagnostic variables to obtain the necessary resolution capability of the sorting unit using the minimum number of data and further to determine algorithms for classifying individual diagnoses. Selected input data of cutting, sliding, wear and fatigue wear particles and soot particles are shown in Tables 3 and 4 and graphical results of the calculations in Figures 9 and 10 [11, 12, 13]. Determining the technical condition, diagnosis and monitoring of engines, transmissions and hydraulic systems involves a system approach that deals with the sampling, analysis and utilization of information that is important in relation to the mechanical state of these systems. Generally it is about monitoring and assessing wearing particles and pollution in fluids (e.g. hydraulic, engine and gear oils), or metal wearing particles monitoring, non-metal polluting particles monitoring, products of burning process by high or low temperatures, soft pollutants of organic origin which form oil resin, so called cold sediments, oil and fuels oxidation products, hard-solid pollutants of inorganic origin, dust particles of silicon origin, etc.

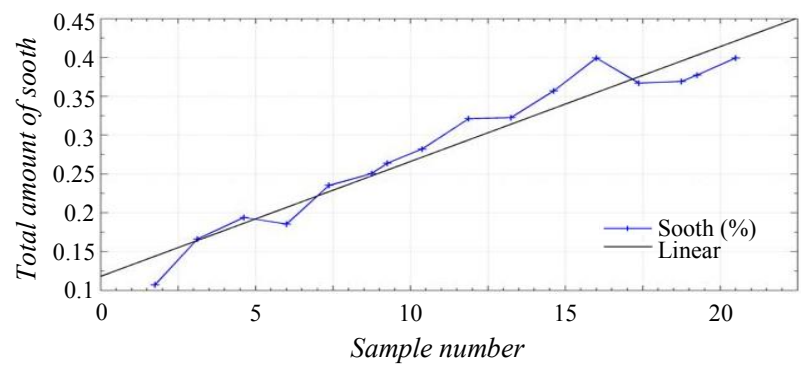

Fig. 9. Example of soot concentrations.

Table 4. Input data of cutting, sliding, fatigue particles.

\begin{tabular}{|c|l|l|l|}
\hline Sample & \multicolumn{1}{|c|}{ Cutting } & \multicolumn{1}{c|}{ Fatigue } & \multicolumn{1}{c|}{ Sliding } \\
\hline 1 & 32.3381511 & 79.69317579 & 46.19006729 \\
\hline 2 & 54.43107224 & 76.42622399 & 48.15056419 \\
\hline 3 & 47.7745769 & 92.84393597 & 55.48026347 \\
\hline 4 & 39.31019068 & 98.55917168 & 47.45829821 \\
\hline 5 & 18.86055315 & 75.44025481 & 49.26862264 \\
\hline 10 & 14.22187865 & 22.54989433 & 9.49721241 \\
\hline 15 & 38.88133812 & 48.50426865 & 48.88801241 \\
\hline 20 & 29.67515659 & 54.72660637 & 90.95250392 \\
\hline 25 & 13.48066711 & 35.8188839 & 39.67050409 \\
\hline 30 & 28.51932859 & 56.26627159 & 49.71670866 \\
\hline 35 & 5.773758411 & 18.86094451 & 12.7022686 \\
\hline 40 & 9.622930765 & 16.93596685 & 17.32127523 \\
\hline 45 & 24.65330708 & 30.81295347 & 32.73876286 \\
\hline 50 & 47.77693057 & 143.7644463 & 84.38728714 \\
\hline 55 & 40.39064407 & 43.0862869 & 5.77009201 \\
\hline 56 & 156.7627567 & 127.6534103 & 90.79354894 \\
\hline 57 & 236.9066696 & 184.4765167 & 175.971869 \\
\hline \multicolumn{3}{|c}{} \\
\hline
\end{tabular}

The monitoring covers a fluid sample collection and its off-line analysis using easy, standard or special instrumental methods. Generation of metallic magnetic particles is usually monitored by magnetic detectors with recording and signalization. Current progressive on-line diagnostic methods use, for example, a laser counter and 
a particle wear classifier, Figures 2 and 3. This method enables us to find wearing particles according to a corresponding wearing mechanism (fatigue, adhesion, abrasion, cavitation, corrosion, vibration, combination of the methods) mentioned above together with expressing the technical state, prognosis, trends calculations, all supported by intelligent software etc.

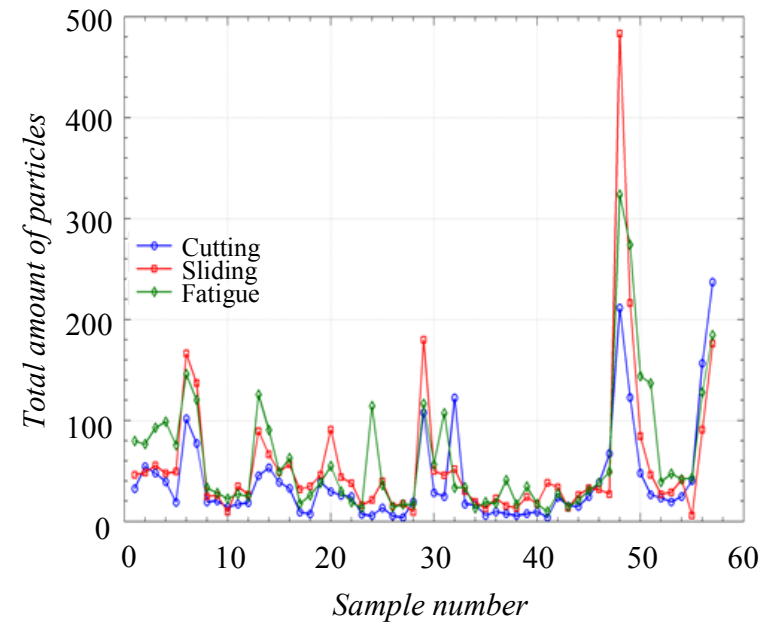

Fig. 10. Total amount of cutting (blue), sliding (red), and fatigue particles (green).

\section{Conclusion}

The paper shows the possibilities of using the FTIR, AES, LNF-C and ferrography methods. These methods allow the identification of pollutants, direct observation of the particles taken from the analyzed oil sample, determination of contaminants, abrasion metals and additives [14, 15]. The briefly described methods were specifically applied in the analysis of motor and gear oil from the powerpack of the special vehicle Figure 10.

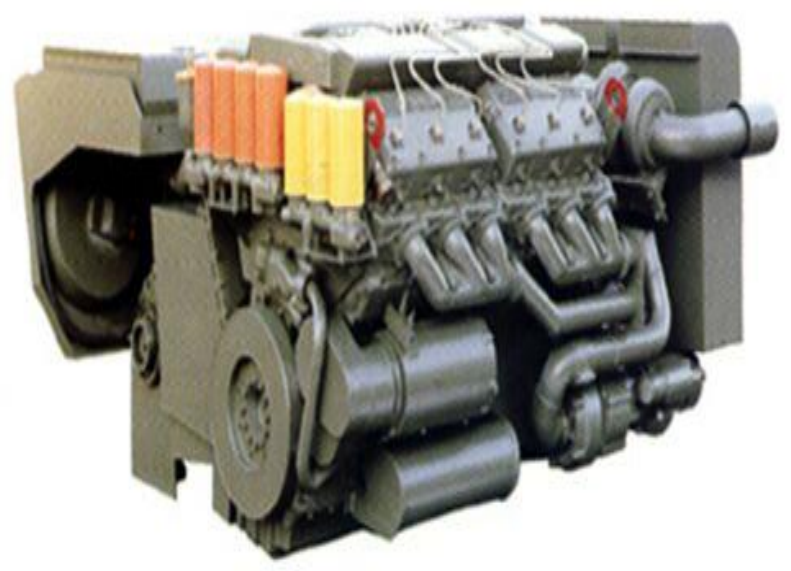

Fig. 11. NIMDA Powerpack [10].

\section{References}

1. L. Deters. Springer Handbook of Mechanical Engineering. Part B. Tribology. ISBN 978-80-540491. p. 295 - 326 (2009)

2. M. Taylor. Quantitative Measures for Shape and Size of Particles, Powder Technology 124, p 94-100 (2001)

3. E. G. Totten. Handbook of Lubrication and Tribology. Volume I. Taylor\&Francis Group. ISBN 0-8493-2095-X London/New York, (2006)

4. Thermo Fisher Stientific [online]. [cit. 2019-01-18]. Available from: http://youtu.be/3LpPJ74koBg

5. F. Tesar. Multidimesional Technical Diasgnostics of the Armed Forxces of the Czech Republic.AČR. Doctoral dissertation. (supervisor J. Stodola). University of Defense Brno, p 100 (2014)

6. J. Glos. Instrumental methods in diagnosing the technical condition of groups of newly introduced combat and special vehicles. Doctoral dissertation. (supervisor J. Stodola). University of Defense Brno, p 103 (2013)

7. J. Stodola. New Recognition Technology for Fluid Systems Contamination. Engineering Mechanics. ISBN 978-80-87012-06-2, p 263 (2007)

8. J. Stodola. Multidimensional Tribodiagnostic Measurements and Their Evaluation. Lubrication Engineering. Illinois, U.S.A., Volume 49, Nr 7, p 513 - 516, (1993)

9. J. Stodola. The Results of Ferrography Test and their Evaluation. Tribotest Journal. Nr. 8 - 1, (8) 73 ISSN 1354-4063. Leaf Coppin, France/England (2001)

10. J. Stodola, P. Novotny. Tribodiagnostic of Combat and Special Vehicles. University script. University of Defense Brno, 2015 ISBN 978-80-7231-984-8, p 104 (2015)

11. M. Koucky, D Valis. On Approaches for NonDestructive Diagnostics and Fuzzy Prognostics. Information Bulletin of the Czech Statistical Society. Vol. 22, no.2 pp.98 - 107 ISSN 1210-8022 (2011)

12. H. Czechos, K. H. Habig. Tribologie-Handbuch; Reibung und Verschleiß, 2nd edition. Weisbaden: Vieweg. (in German). (2003)

13. C. R. Bill, D. Wisander. Recrystallization as a Controlling Process in the Wear of Some F.C.C. Metals Wear. Vol. 41. pp. 351-363. (1977)

14. H. D. Buckley. Surface Effects in Adhesion, Friction. Wear and Lubrication, Elsevier, Amsterdam, (1981)

15. J. Furch, Z. Krobot, J. Stastny, T. Turo. Using Telemetry for Maintenance of Special Military Vehicles. In: Modelling and Simulation for Autonomous System: Springer International Publishing. ISSN 0302-9743. ISBN 978-3-31976071-1. Pp 392- 401. (2018) 